\title{
Caracterización de la citología prepucial en perros adultos
}

\author{
Sánchez, A.E. \\ Escuela de Medicina Veterinaria, Facultad de Veterinaria y Agronomía, \\ Universidad de Las Américas, Viña del Mar, Chile. E-mail: asanchez@udla.cl
}

\begin{abstract}
Resumen
Sánchez, A.E.: Caracterización de la citología prepucial en perros adultos. Rev. Vet. 31: 1, 89-91, 2020. Con el objetivo de caracterizar la citología prepucial en perros adultos clínicamente sanos, se muestrearon 50 perros de entre 1 y 12 años, formándose 2 grupos etarios: 1 a 4 años $(n=25)$ y $>5$ años $(n=25)$ para realizar una comparación. Se realizó examen físico y ultrasonográfico para descartar presencia de neoplasias testiculares. La edad promedio en los grupos fue de 2,78 $\pm 1,43$ años y 7,82 $\pm 3,12$ años, respectivamente. Los recuentos de células epiteliales totales incluyeron células parabasales: $24,32 \pm 14,01$; células intermedias: 73,07 $\pm 24,32$; y células superficiales: $2,69 \pm 1,45$. No se observaron diferencias estadísticas entre grupos. El recuento de neutrófilos arrojó una mayor frecuencia de las categorías moderada y abundante en ambos grupos etarios $(\mathrm{p} \leq 0,05)$. El presente estudio caracteriza la citología prepucial normal en perros adultos sanos de diferentes edades, con predominio de células intermedias y cantidad abundante a moderada de neutrófilos.
\end{abstract}

Palabras clave: perros sanos, prepucio, neutrófilos, células parabasales, intermedias y superficiales.

\begin{abstract}
Sánchez, A.E.: Characterization of preputial cytology in adult dogs. Rev. Vet. 31: 1, 89-91, 2020. In order to characterize the preputial cytology in clinically healthy adult dogs, 50 dogs between 1 and 12 years old were sampled, forming 2 groups: 1 to 4 years-old $(n=25)$ and $>5$ years-old $(\mathrm{n}=25)$, to perform a comparison. A physical and ultrasonographic examination was performed to rule out the presence of testicular tumors. The average age in groups was $2.78 \pm 1.43$ years and $7.82 \pm 3.12$ years, respectively. The total epithelial cell counts were: parabasal cells $=24.32 \pm 14.01$; intermediate cells $=73.07 \pm 24.32$; superficial cells $=2.69 \pm$ 1.45. No statistical differences between groups were observed. The neutrophils count showed a higher frequency of the moderate and abundant categories in both groups $(\mathrm{p} \leq 0.05)$. The present study characterizes normal preputial cytology in healthy adult dogs of different ages, with predominance of intermediate cells and moderate to abundant neutrophils.
\end{abstract}

Key words: healthy dogs, foreskin, neutrophil, parabasal, intermediate and superficial cells.

\section{INTRODUCCIÓN}

El prepucio corresponde a un pliegue de tegumento o vaina tubular que se continúa con la piel de la pared ventral del abdomen y se refleja sobre el glande. Posee una capa lisa profunda y otra superficial cubierta de pelo que confluyen en el orificio prepucial. Como su fondo de saco o fórnix es más profundo, la capa media se refleja sobre el glande ${ }^{3}$.

La piel del pene constituye una fina envoltura, fácilmente deslizable sobre los planos profundos y con una coloración ligeramente más obscura al resto del tegumento. En la zona más distal se encuentra el prepucio, que forma un manguito cutáneo que envuelve al glande mediante el surco balano-prepucial y otra distal $\mathrm{o}$ anterior libre conocida con el nombre de orificio prepucial.

Recibido: octubre 2019 / Aceptado: diciembre 2019
Al nacimiento, el pene no se halla libre en la cavidad prepucial, ya que las superficies epiteliales del pene y la vaina están adheridas al pliegue balano-prepucial. Dicho pliegue se desdobla en una capa visceral y otra parietal por virtud de un proceso citolítico que forma vesículas, las cuales al fusionarse dan origen a la cavidad prepucial. La separación de las capas visceral y parietal se halla subordinada a la influencia de los andrógenos ${ }^{6}$.

La lámina interna del prepucio está recubierta por una membrana mucosa, constituida por epitelio plano estratificado, no queratinizado. La mucosa prepucial se hace continua con la mucosa del pene en el fórnix. En la cara interna del prepucio se encuentra tejido linfoide y abundantes glándulas sebáceas modificadas, cuya secreción se denomina esmegma ${ }^{5}$.

En la clínica reproductiva canina es común el estudio de la citología vaginal para monitorear el ciclo estral ${ }^{4}$. Por otra parte, la citología prepucial ha sido eva- 
luada como prueba para el diagnóstico de neoplasias testiculares secretoras de estrógenos en perros, presentando alta sensibilidad y especificidad en pacientes con dermatopatía endocrina por hiperestrogenismo ${ }^{2}$. No obstante estos antecedentes, existe escasa información sobre la citología prepucial en perros sanos.

Por esta razón, el objetivo del presente estudio fue caracterizar la citología prepucial en perros adultos clínicamente sanos y realizar una comparación de la misma entre dos grupos etarios.

\section{MATERIAL Y MÉTODOS}

Mediante un muestreo por conveniencia y con el consentimiento de sus propietarios, se investigaron 50 perros de diferentes razas y pesos entre 2,8 y $86,7 \mathrm{~kg}$, clínicamente sanos al examen clínico general, mayores de 1 año de edad. El criterio de inclusión consideró la presencia de ambos testículos en el escroto, sin neoplasia evidente. El estudio se realizó entre enero de 2018 y enero 2019.

Los ejemplares fueron evaluados en el Centro Veterinario de la Universidad de Las Américas sede Viña del Mar (Chile). Se conformaron dos grupos etarios: grupo A (1 a 4 años de edad, $n=25)$ y grupo $B(\geq 5$ años de edad, $n=25$ ). El protocolo de trabajo con animales, fue aprobado por el Comité de Ética Científica de la Universidad de Las Américas (UDLA, Chile).

El examen reproductivo consideró palpación y ecografía testicular. La citología prepucial se realizó mediante hisopado del fórnix (Foto 1) y extendido sobre portaobjetos en duplicado para cada ejemplar examinado. Para la tinción se utilizó el producto comercial $M G G$ Quick Stain (Bio Optica Milano). Los frotis fueron secados al aire y luego se realizó la evaluación mediante microscopia óptica con objetivos de x10 y x 40, contándose 200 células en cada muestra.

Las células se clasificaron de acuerdo con los criterios morfológicos utilizados en los frotis vaginales: (1) parabasales (pequeñas células redondas con núcleos vesiculados redondos y una pequeña cantidad de citoplasma), (2) intermedias (células grandes con núcleos vesiculados, normales o irregulares, citoplasma plegado y angular) y (3) superficiales (células grandes con un núcleo pequeño, picnótico, débil o nulo, citoplasma abundante, angular y plegado) ${ }^{4}$. Además, se consignó la presencia de neutrófilos en 4 categorías: ausencia (-), escasa $(+)$, moderada $(++)$ y abundante $(+++)$.

Con los recuentos celulares, los datos porcentuales fueron trasformados a valores angulares (ángulo $=$ arcoseno $\mathrm{x}$ ) para llevarlo a la distribución normal $\mathrm{y}$ realizar un análisis unilateral de la variancia. Las diferencias se estimaron mediante la prueba de hipótesis específica de Tukey. Las categorías de presencia de neutrófilos se analizaron mediante el test no paramétrico Mann-Whitney. Todos los análisis estadísticos fueron realizados con el programa estadístico STATA 14, considerando un $95 \%$ de confianza.
Tabla 1. Recuento de células epiteliales en hisopados prepuciales de perros adultos sanos de dos grupos etarios.

\begin{tabular}{lcc}
\hline \multirow{2}{*}{$\begin{array}{l}\text { tipo } \\
\text { celular }\end{array}$} & \multicolumn{2}{c}{ grupo etario } \\
\cline { 2 - 3 } parabasal $(\%)$ & $1-4$ años $(\mathrm{n}=25)$ & $\geq 5$ años $(\mathrm{n}=25)$ \\
intermedia $(\%)$ & $71,98 \pm 23,21 \pm 15,56$ & $23,85 \pm 12,72$ \\
superficial $(\%)$ & $2,80 \pm 1,33$ & $74,50 \pm 25,67$ \\
\hline
\end{tabular}

\section{RESULTADOS Y DISCUSIÓN}

La edad promedio en los grupos A y B fue de 2,78 \pm 1,43 años y 7,82 $\pm 3,12$ años respectivamente. El rango de edad en la muestra total fluctuó entre 1 y 12 años. Respecto al criterio de inclusión podemos señalar que en el examen físico reproductivo se registraron mayores frecuencias de anomalías testiculares, tales como asimetría y tono disminuido en el grupo de perros $\geq 5$ años.

Respecto de ejemplares más jóvenes y en la evaluación ultrasonográfica se pudo observar una mayor frecuencia de alteraciones del parénquima testicular, especialmente heterogeneidad y presencia de focos anecoicos en los perros $\geq 5$ años versus el grupo de 1 a 4 años.

Cabe considerar que en el examen andrológico de individuos de mayor edad se evidencian alteraciones testiculares que incluyen una disminución del parénquima gonadal, fenómeno asociado a degeneración y atrofia testicular ${ }^{8}$. Se ha descripto que los cambios degenerativos en los testículos caninos son más pronunciados sobre los 9 años de edad ${ }^{1}$. No obstante estos hallazgos, se pudo descartar la presencia de neoplasias testiculares evidentes en todos los casos registrados.

En el estudio de la citología prepucial (Foto 2), los recuentos de células epiteliales totales fueron: parabasales: $24,32 \pm 14,01$; intermedias: $73,07 \pm 24,32$ y superficiales: $2,69 \pm 1,45$. No se observaron diferencias estadísticas entre los grupos etarios (Tabla 1).

Estos hallazgos son coincidentes con los descritos en perros sanos, donde el rango de células superficiales

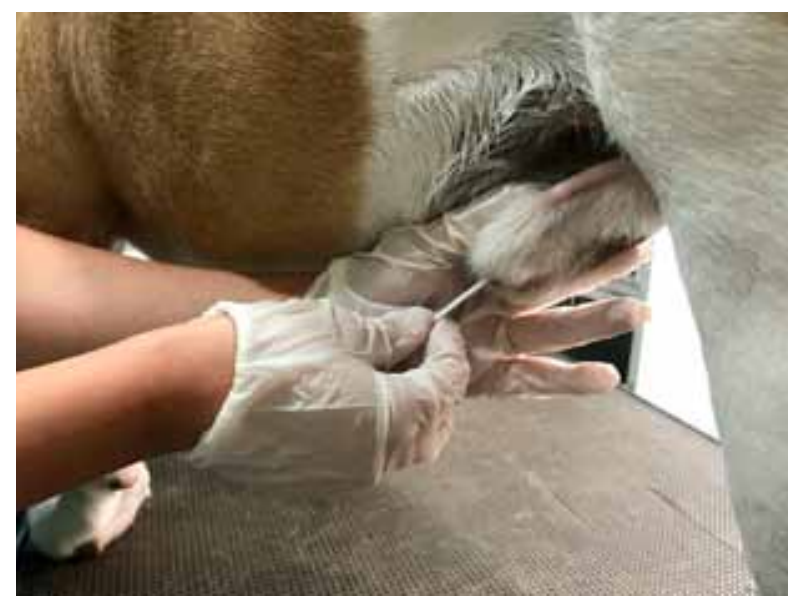

Foto 1. Obtención de frotis prepucial de un canino. 
en frotis prepuciales varía entre 0 a $14 \%$, destacando que sobre un $20 \%$ debiese ser considerado anormal, tal como ocurre en el caso de tumores testiculares secretores de estrógenos ${ }^{2}$.

El recuento de neutrófilos (Foto 3) arrojó una mayor frecuencia de las categorías moderada y abundante para ambos grupos etarios $(\mathrm{p} \leq 0,05)$. Ello podría explicarse por la presencia de pequeñas cantidades de esmegma amarillo-blanquecino, abundante en células epiteliales, células inflamatorias (principalmente neutrófilos) y bacterias, que se acumulan alrededor del orificio prepucial ${ }^{4}$.

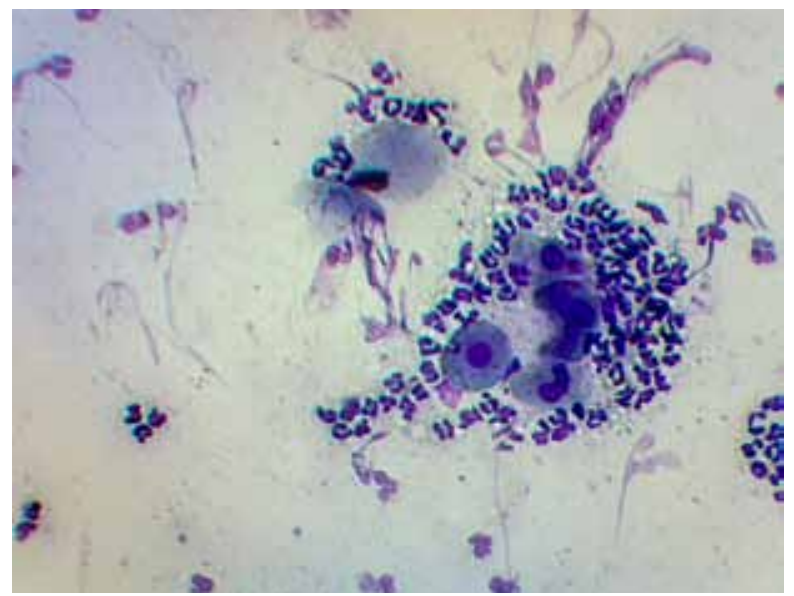

Foto 2. Frotis prepucial mostrando células intermedias, así como moderada cantidad de neutrófilos.

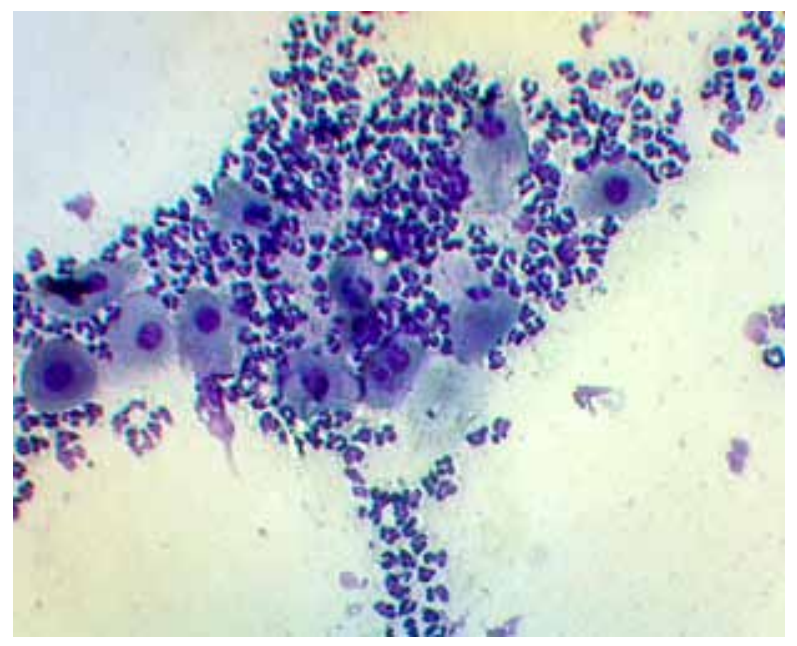

Foto 3. Frotis prepucial revelando células intermedias y abundante cantidad de neutrófilos.
El presente estudio caracteriza la citología prepucial normal en perros adultos sanos de diferentes edades, con un predominio de células intermedias y moderada a abundante cantidad de neutrófilos, permitiendo considerar estos resultados como una referencia para la actividad clínica ${ }^{7}$. Además, el estudio citológico de la mucosa prepucial podría ser valorado como un elemento complementario en la evaluación de la salud reproductiva en perros.

Agradecimiento. A las Dras. Carolina Fierro y Francisca Troya por la colaboración en la obtención de los pacientes. A la Dirección de Investigación de la Universidad de Las Américas (Viña del Mar, Chile) por el financiamiento a través del proyecto interno 2802018.

\section{REFERENCIAS}

1. Bhanmeechao C, Srisuwatanasagul S, Ponglowhapan S. 2018. Age-related changes in interstitial fibrosis and germ cell degeneration of the canine testis. Reprod Dom Anim 53: 37-43.

2. Dreimanis U, Vargmar K, Falk T, Cigut M, Toresson L. 2012. Evaluation of preputial cytology in diagnosis oestrogen producing testicular tumours in dogs. J Small Anim Pract 53: 536-541.

3. Evans H, Lahunta A. 2002. Abdomen, pelvis y miembro locomotor pelviano. En: Disección del perro (Evans H, Lahunta A, Ed), McGraw-Hill Interamericana, México, p. 236-237.

4. Feldman E, Nelson R. 1996. Canine male reproduction. In: Canine and feline endocrinology and reproduction (Feldman E, Nelson R, Ed), $2^{\text {nd }}$ ed., W.B. Saunders Co., Philadelphia, p. 691-696.

5. Gartner L, Hiatt J. 2008. Sistema reproductor masculino. En: Texto atlas de histología (Gartner L, Hiatt J, Ed), McGraw-Hill Interamericana, México, p. 236-237.

6. Pineda M. 2003. Male reproductive system. In: McDonald's Veterinary Endocrinology and Reproduction (Pineda M, Dooley M, Ed), $5^{\text {th }}$ ed. Iowa State Press, Iowa, p. 261-262.

7. Sánchez A. 2018. Salud reproductiva del macho canino. Invest Cienc Anim 2: 33-36.

8. Schäfer S. 2015. New approaches to semen improvement in dogs. Rev Bras Reprod Anim 39: 141-145. 